Original Article (short paper)

\title{
Influence of age, sex, and visual information on postural control in children
}

\author{
Leonardo Vitor George Victorio $^{1}\left[\right.$, Dirce Shizuko Fujisawa ${ }^{10}$ \\ ${ }^{1}$ Universidade Estadual de Londrina, UEL, Department of Physical Therapy, Londrina, PR, Brazil
}

\begin{abstract}
Aim: This study aims to evaluate and identify the influence of age, sex, and visual information on postural control in children. Methods: Participants were 62 children ( 30 boys and 32 girls) divided into the following age groups (G): G1, aged 5-6 years $(n=23)$; G2, aged 7-8 years $(n=21)$; and $G 3$, aged 9-10 years $(n=18)$. The analyzed variables were the center of pressure (COP) and anteroposterior (AP) and mid-lateral (ML) oscillation velocity (OV) obtained in the biped posture force platform with their open eyes (OE) and closed eyes (CE). Results: G3 COP, OV_AP, and OV_ML are smaller than those in G1 and G2 in OE $(p<0.00)$ and CE $(p<0.05)$. Girls demonstrated worse postural control than boys for COP, OV_AP, and OV_ML $(p<0.00)$ in G1. Conclusion: Age was the most influential factor of COP (21\%), OV_AP (24\%), and OV_ML (39\%). Older children perform better, because of the positive contribution of visual information. Girls initially had worse postural control responses, but at age 7-8, they tend to outgrow boys. Advanced age provides more influence on postural control than visual information and sex.
\end{abstract}

Keywords: children, postural control, sex, visual acuity.

\section{Introduction}

Children encountered various changes in their motor behavior throughout their development, such as the development of postural control (PC). PC is an essential factor for functionality because it enables body balance in different positions and allows the performance of various activities. The balance represents the moment wherein a body stands without falling, i.e., the gravity line is within the support base ${ }^{1}$. PC is the body's motor adjustment to maintain or restore the gravity line within the supporting base $\mathrm{e}^{1,2}$. To achieve balance, the central nervous system receives visual, vestibular, and somatosensory information, and then modulates and organizes strategies via muscle contraction or relaxation to generate body movement to reach or recover balance ${ }^{2}$.

Visual information provides feedback for balance, and the visual system captures light and identifies images so that individuals can control, guide, and move objects and even body segments to avoid obstacles and overcome environmental difficulties ${ }^{3}$. Vestibular information helps in the perception of acceleration, and the somatosensory information identifies contact with objects, soil types, and segment positions through receptors or sensors ${ }^{2,4}$.

As individuals evolve, their body systems develop, to optimize and create strategies appropriate for the situation. Initially, visual information is the basis for a child to attain $\mathrm{PC}^{5}$. In infants aged 5-10 months, visual information helps with adjustments of a seated position ${ }^{5,6}$. At the age of 6 years, children's maintenance of bipedal posture with eyes open (EO) is better than that at age of 3 years, but with closed eyes (CE), balance performance is equivalent among children at those ages, suggesting strong visual interference $e^{7,8}$. From 7 to 12 years of age, children generate balance responses similar to adults, but they still use the visual system's contribution ${ }^{9,10,11}$.
Regarding sex, girls aged 7-12 years have better balance accuracy than boys and show greater systems integration. For adults, no differences were found in their balance response regardless of $\operatorname{sex}^{12,13}$.

Understanding PC deficits for decision making in these age groups is difficult, as several intrinsic and extrinsic factors exist. Motor experience is a determinant for a good PC. However, other characteristics, such as sex and visual information, are relevant. Moreover, identifying what influence these characteristics during normal motor development is important ${ }^{2}$.

The aim of this study was to verify PC differences in children of different ages and sex regardless of visual information and to assess the influence of these factors on measured variables of the children.

\section{Methods}

This cross-sectional study was performed with a sample of 62 children from the Municipal Education schools. Inclusion criteria were healthy children of both sexes and aged 5-10 years. Exclusion criteria were the presence of acute or chronic diseases, surgery and bone fractures, deformities, continuous use of medication, and physical and/or sensory impairment.

The study protocol and informed consent form were approved by the Ethics Committee (CAAE 0019.0.268.000-10, No. 020/2010). The Municipal Department of Education approved the study. Parents or guardians approved the evaluation and signed the informed consent form. When a child with a balance deficit was identified, the responsible teacher would receive assessment results to foster physical activities that promote PC. If there were children with significant deficits, parents would be 
advised to seek evaluation and monitoring at the primary health care unit within their school or home coverage area.

\section{Characterization of the sample}

Participating children (30 boys and girls 32) were divided into the following three groups according to age: $\mathrm{G} 1,5(\mathrm{n}=16)$ and 6 years old $(n=7) ; G 2,7(n=15)$ and 8 years old $(n=6)$; $\mathrm{G} 3,9(\mathrm{n}=8)$ and 10 years old $(\mathrm{n}=10)$ Identification data were collected through a questionnaire previously answered by parents or guardians to verify the presence of the exclusion criteria. The physical examination consisted of body mass measurement in kilograms (G1, $19.5 \mathrm{~kg} \pm 3.90 ; \mathrm{G} 2,25.5 \mathrm{~kg} \pm 2.93$; and $\mathrm{G} 3$, $37.8 \mathrm{~kg} \pm 2.29)$ and height (G1, $1.11 \mathrm{~m} \pm 0.06 ; \mathrm{G} 2,1.28 \mathrm{~m} \pm 0.04$; and $\mathrm{G} 3,1.42 \mathrm{~m} \pm 0.09)$.

\section{Force platform (FP)}

PC was quantified according to the vertical force distribution at 4 points to obtain objective and sensitive data. The FP used was BIOMEC400 (EMG System of Brasil Ltda. (SP), with two sensors that recorded the contact of the feet on the ground, and channels were configured to force, with filters in the frequency band between 0 and $35 \mathrm{~Hz}$. The parameters analyzed by stabilometry were the center of the pressure area $\left(\mathrm{COP} / \mathrm{cm}^{2}\right)$ and mean speeds $(\mathrm{OV} / \mathrm{cm} / \mathrm{s})$ in both oscillation directions AP and ML. FP signs were also processed and handled using the stabilometry analysis system BIOMEC400. The parameters used were confirmed valid and reliable for balance assessment ${ }^{14}$.

The evaluation protocol was standardized in relation to the length of time ( 15 seconds of maintenance in each posture) in bipedal position with $\mathrm{OE}$ and $\mathrm{CE}$. Each position was evaluated by two attempts, and the mean of the two measurements was used for analysis. Evaluations were individually performed in a peaceful environment, and participating children were barefoot with a neutral support base, i.e., they were instructed to stand with their feet apart "distanced according to hip width." The child's gaze was directed to a reference point at eye level with a front distance of $2.5 \mathrm{~m}$, and their arms relaxed and hanging on their sides.

The tests were applied by previously trained staff, and data collection was standardized. The trained staff was instructed to position themselves close to the children to prevent them from falling, but without interfering with their performance.

The heterogeneity of the body mass was assumed $(p=0.00)$, and for stature, the sample behaved homogeneously $(p=0.20)$ according to the Kolmogorov-Smirnov test. Therefore, to ensure that the data did not affect the measured variables, avoiding internal errors, linear regression analysis of the variable nutritional classification score $\mathrm{Z}$ (which determines the proportion of body mass in relation to height, age, and sex) was performed to identify how it could influence results, and it did not show a significant influence $\left(\mathrm{R}^{2}-\operatorname{sig} \mathrm{F}\right.$ : COP, $0.01-0.20$; OV_AP, $0.00-0.62$; and OV_ML, $0.01-0.21$ ) or interaction (Pearson: COP, 0.12; OV_AP, 0.05; and OV_ML, 0.06) ${ }^{15}$.

\section{Statistical analysis}

Data were analyzed using two-way analysis of variance (ANOVA) and the Tukey post-hoc test. The assumptions of ANOVA were accepted, such that the homogeneity of the variances and residuals follow a normal distribution. Statistical significance was set at $\mathrm{p} \leq 0.05$. Results were presented as mean and standard deviation. Linear regression was performed to identify the variables' coefficient of determination on PC performance and Pearson correlation for interaction degree and direction.

\section{Results}

Older children showed better PC performance regardless of visual information. When deprived of visual information, PC worsened in all groups for both sexes. Younger boys (G1) showed better PC compared to girls regardless of visual information (Table 1). Intergroup and intragroup significant differences were also observed.

Table 1. PC performance according to age regardless of visual information and sex: intergroup and intragroup differences

\begin{tabular}{|c|c|c|c|c|c|c|c|c|}
\hline \multicolumn{9}{|c|}{ COP } \\
\hline & \multicolumn{2}{|c|}{ OE } & \multicolumn{2}{|c|}{$\mathbf{C E}$} & \multicolumn{2}{|c|}{ GIRLS } & \multicolumn{2}{|c|}{ BOYS } \\
\hline & Mean & SD & Mean & SD & Mean & SD & Mean & SD \\
\hline G1 & 3.99 & 3.14 & 5.67 & 3.61 & 5.50 & 3.30 & 2.32 & 1.74 \\
\hline G2 & 2.11 & 1.24 & 3.61 & 1.62 & 1.93 & 1.22 & 2.01 & 1.35 \\
\hline G3 & 1.40 & 0.72 & 2.27 & 1.18 & 1.43 & 0.43 & 1.38 & 0.91 \\
\hline$p>0.05$ & \multicolumn{4}{|c|}{$a, b, c, d, e, f, g$} & \multicolumn{4}{|c|}{$b, 1,2,3,4,5,6$} \\
\hline \multicolumn{9}{|c|}{ OV_AP } \\
\hline & \multicolumn{2}{|c|}{ OE } & \multicolumn{2}{|c|}{ CE } & \multicolumn{2}{|c|}{ GIRLS } & \multicolumn{2}{|c|}{ BOYS } \\
\hline & Mean & SD & Mean & SD & Mean & SD & Mean & SD \\
\hline G1 & 1.71 & 0.40 & 2.10 & 0.62 & 1.89 & 0.42 & 1.58 & 0.30 \\
\hline G2 & 1.37 & 0.21 & 1.84 & 0.48 & 1.35 & 0.36 & 1.40 & 0.22 \\
\hline G3 & 1.13 & 0.25 & 1.45 & 0.33 & 1.09 & 0.13 & 1.17 & 0.30 \\
\hline$p>0.05$ & \multicolumn{4}{|c|}{$a, b, c, d, f, g, h, i, j, k$} & \multicolumn{4}{|c|}{$b, 2,3,4,5,6,7,8,9$} \\
\hline \multicolumn{9}{|c|}{ OV_ML } \\
\hline & \multicolumn{2}{|c|}{$\mathrm{OE}$} & \multicolumn{2}{|c|}{$\mathrm{CE}$} & \multicolumn{2}{|c|}{ GIRLS } & \multicolumn{2}{|c|}{ BOYS } \\
\hline & Mean & SD & Mean & SD & Mean & SD & Mean & SD \\
\hline G1 & 1.54 & 0.32 & 1.71 & 0.40 & 1.62 & 0.36 & 1.44 & 0.22 \\
\hline G2 & 1.28 & 0.22 & 1.42 & 0.30 & 1.25 & 0.22 & 1.31 & 0.22 \\
\hline G3 & 0.97 & 0.18 & 1.09 & 0.25 & 0.94 & 0.14 & 1.00 & 0.20 \\
\hline$p>0.05$ & \multicolumn{4}{|c|}{$a, b, c, d, e, f, g, j, k, l, m, n$} & \multicolumn{4}{|c|}{$b, 3,4,5,6,7,8,9,10,11,12$} \\
\hline \multicolumn{9}{|c|}{$\begin{array}{l}\text { Mean and standard deviation groups, visual information, } \\
\text { and sex. } P \text { values found for two-way ANOVA and TUKEY } \\
\text { post-hoc test: } a \mathrm{OE}<\mathrm{CE} ; b \mathrm{G} 1>\mathrm{G} 2>\mathrm{G} 3 ; c \mathrm{G} 1 \mathrm{OE}>\mathrm{G} 3 \mathrm{OE} ; \\
d \mathrm{G} 1 \mathrm{CE}>\mathrm{G} 2 \mathrm{OE} ; e \mathrm{G} 1 \mathrm{CE}>\mathrm{G} 2 \mathrm{CE} ; f \mathrm{G} 1 \mathrm{CE}>\mathrm{G} 3 \mathrm{OE} \text {; } \\
g \mathrm{G} 1 \mathrm{CE}>\mathrm{G} 3 \mathrm{CE} ; h \mathrm{G} 1 \mathrm{OE}>\mathrm{G} 1 \mathrm{CE} ; i \mathrm{G} 2 \mathrm{CE}>\mathrm{G} 2 \mathrm{OE} ; j \mathrm{G} 2 \mathrm{CE}>\mathrm{G} 3 \mathrm{OE} ; \\
k \mathrm{G} 2 \mathrm{CE}>\mathrm{G} 3 \mathrm{CE} ; l \mathrm{G} 2 \mathrm{OE}>\mathrm{G} 3 \mathrm{OE} ; m \mathrm{G} 1 \mathrm{OE}>\mathrm{G} 3 \mathrm{CE} \text {; } \\
n \mathrm{G} 1 \mathrm{OE}>\mathrm{G} 2 \mathrm{OE} .1 \mathrm{BOYS}>\mathrm{GIRLS} ; 2 \mathrm{G} 1 \mathrm{BOYS}<\mathrm{G} 1 \mathrm{GIRLS} ; \\
3 \mathrm{G} 1 \mathrm{BOYS}>\mathrm{G} 2 \mathrm{BOYS} ; 4 \mathrm{G} 1 \mathrm{BOYS}>\mathrm{G} 2 \mathrm{GIRLS} ; \\
5 \mathrm{G} 1 \mathrm{BOYS}>\mathrm{G} 3 \mathrm{BOYS} ; 6 \mathrm{G} 1 \mathrm{BOYS}>\mathrm{G} 3 \mathrm{GIRLS} ; \\
7 \mathrm{G} 1 \mathrm{GIRLS}>\mathrm{G} 3 \mathrm{BOYS} ; 8 \mathrm{G} 1 \mathrm{GIRLS}>\mathrm{G} 3 \mathrm{GIRLS} ; \\
9 \mathrm{G} 2 \mathrm{GIRLS}>\mathrm{G} 3 \mathrm{BOYS} ; 10 \mathrm{G} 2 \mathrm{BOYS}>\mathrm{G} 3 \mathrm{BOYS} ; \\
11 \mathrm{G} 2 \mathrm{BOYS}>\mathrm{G} 3 \mathrm{GIRLS} ; 12 \mathrm{G} 2 \mathrm{GIRLS}>\mathrm{G} 3 \mathrm{GIRLS}\end{array}$} \\
\hline
\end{tabular}


The influence of age, visual information, and sex on PC was observed, and aging showed a greater determination of improved performance. In addition, influencing factors had a higher determining strength for OV_AP, and OV_ML than COP (Table 2).

Table 2.Factors influencing postural control among children

\begin{tabular}{lcccccccccc}
\hline & \multicolumn{3}{c}{ AGE } & \multicolumn{4}{c}{ VISUAL INFORMATION } & \multicolumn{2}{c}{ SEX } \\
\cline { 2 - 9 } & $\mathbf{R}^{\mathbf{2}}$ & $\operatorname{sig} F$ & Pearson & $\mathbf{R}^{\mathbf{2}}$ & $\mathbf{s i g} F$ & Pearson & $\mathbf{R}^{\mathbf{2}}$ & sig $F$ & Pearson \\
\hline COP & 0.21 & 0.00 & -0.46 & 0.05 & 0.01 & 0.23 & 0.10 & 0.00 & -0.31 \\
OV_AP & 0.24 & 0.00 & -0.49 & 0.13 & 0.00 & 0.26 & 0.03 & 0.17 & -0.17 \\
OV_ML & 0.39 & 0.00 & -0.62 & 0.03 & 0.03 & 0.18 & 0.03 & 0.07 & -0.15 \\
\hline
\end{tabular}

Parameters: $\mathrm{PC} \times$ factors, $\mathrm{R}^{2}$ coefficient of explanation; sig $F$ value of signification; Pearson value and direction correlation. COP, center of the pressure area $\left(\mathrm{COP} / \mathrm{cm}^{2}\right)$ and mean speeds $(\mathrm{OV} / \mathrm{cm} / \mathrm{s})$ in both oscillation directions; AP ML.

\section{Discussion}

The results of this study show that age affects PC performance of both girls and boys regardless of visual information. Children with typical development have a lower $\mathrm{COP}$ area and $\mathrm{OV}$ in both directions with increasing age. This result supports the findings of a previous study ${ }^{16}$.

Boys perform better at a younger age ( $\mathrm{G} 1$ boys $<\mathrm{G} 1$ girls), but as they age, girls aged 7-8 years had lower COP and OV AP ML values. Thereafter, both boys and girls have comparable performances. This fact may be related to the evident maturation process from age 7 to 10 years ${ }^{17}$.

Deprivation of visual information worsens PC performance, especially when children are younger. As children age, they become less dependent on visual information, for example, the COP area in $\mathrm{G} 1 \mathrm{EO} / \mathrm{EC}$ was $3.99 \mathrm{~cm}^{2} / 5.67 \mathrm{~cm}^{2}$ and that in $\mathrm{G} 3 \mathrm{EO} / \mathrm{EC}$ was $1.40 \mathrm{~cm}^{2} / 2.27 \mathrm{~cm}^{2}$. They presented different magnitudes, so the absence of visual information created greater difficulty for younger children. Previous studies have reported that the transition period where in PC is no longer strictly dependent on vision is around age $7^{18,19,20}$. However, PC and systems still continue to mature until around 12 years and only mature at around 15 years ${ }^{13}$. Thus, during testing, increased COP and OV_AP ML values were found in 24-year-old adults without visual information, but they were not significant ${ }^{21}$. There are significant differences between EO and EC moments for 11-year-old children ${ }^{22}$. This fact comprises the performance improvement of the older groups when comparing $\mathrm{OE}$ and $\mathrm{CE}$ moments. Therefore, vision is essential in the PC development process, and tendentiously, its influence decreases with aging.

Age showed a greater influence on $\mathrm{PC}$ performance (Table 2 ), explaining the improvement of $21 \%$ for COP, $24 \%$ for OV_AP, and 39\% for OV_ML during development. Aging makes children discover new strategies and ways to control their center of gravity within the supporting base, both in reactive and predictive moments ${ }^{13}$. Age has a higher magnitude of influence on $\mathrm{OV} M L$ and has the strongest correlation among all variables $(\mathrm{r}-0 . \overline{62})$ because this type of oscillation is a more advanced strategy more common in older children. The AP plan includes a simpler strategy of balance recovery or reaction, which is triggered by the plantar and dorsal muscles of the ankle joints. Moreover, with PC variability from the infant period, the child has more AP strategy to maintain sitting and dorsal decubitus positions $^{22}$. On the contrary, the ML plan corresponds to hip strategies in more extreme oscillation situations ${ }^{23}$.

Table 2 shows that the visual system proved to be more influential for OV_AP (13\%) than COP (5\%) and OV_ML (3\%), probably because the AP oscillation is the baseline, as the threshold for detecting AP oscillations is less than that for ML. This implies that ML oscillation stabilization is underestimated compared to AP without visual information ${ }^{25}$.

Sex had more influence on the COP, in which $10 \%$ of the variation was due to the difference between boys and girls. Younger girls (G1) had worse performance, which was overcome only as they aged. This change (sex) had a weak correlation $(\mathrm{r}=-0.31)$. The performance improvement in girls is probably more correlated with aging because its rates have greater strength for all evaluated COP parameters $(r=-0.46)$, OV_AP $(\mathrm{r}=-0.49)$, and OV_ML $(\mathrm{r}=-0.62)$. Steind $\mathrm{l}^{13}$ stated that the integration of sensory systems in girls develops fast. In their analysis, boys kept PC with less precision than girls at age 7 and 8 .

The evaluation system adopted (FP) was efficient for evaluating the objectives proposed in this study. A field study found a relationship between $\mathrm{PC}$ improvement and aging, which also proved to be more influential in PC evolution, corroborating the presented results, although sex factor contribution was not found ${ }^{26}$. Although this study could quantify the extent of this influence, the methodology proposed using the FP is more sensitive for PC identification. Another aspect is the time spent on the FP at the time of assessment. Similar studies used 20 seconds ${ }^{19}$ and 30 seconds $^{13}$; however, 15 seconds in a given position was sufficient to detect intragroup and intergroup changes in PC. Functional tests, such as the Pediatric Balance Scale, used 10 seconds in bipedal stance with eyes closed, which was sufficient to show better or worse performance ${ }^{27}$.

\section{Conclusion}

Briefly, PC development occurs with aging, probably due to the greater exposure to the environment favoring motor experiences. Age was the most influential factor in PC performance in children aged 5-10 years. Boys aged 5-6 years initially showed better performance than girls; however, at age 7-8 years, they were overtaken by girls. Deprivation of visual 
information negatively influences $\mathrm{PC}$ at all ages, regardless of sex. The limitation of the current study was the small sample size, but the size is enough to address the study aims.

\section{References}

1. Pollock AS, Durward BR, Rowe PJ, Paul JP. What is balance? Clin Rehabil 2000; 14: 402-406.

2. Sibley KM, Beauchamp MK, Van Ooteghem K, Straus SE, Jaglal SB. Using the systems framework for postural control to analyze the components of balance evaluated in standardized balance measures: a scoping review. Arch Phys Med Rehab. 2015; 96(1): 122-132.

3. de Sá CDSC, Boffino, CC, Ramos RT, Tanaka C. Development of postural control and maturation of sensory systems in children of different ages a cross-sectional study. Braz J PhysTher. 2018; 22(1): 70-76.

4. Mochizuki L, Duarte M, Amadio AC, Zatsiorsky VM, Latash ML. Changes in Postural Sway and Its Fractions Conditions of Postural Instability. J Applied Biomech 2006; 22: 51-60.

5. Arienti, C, Buraschi R, Donzelli S, Zaina F, Pollet J, Negrini S. Trunk asymmetry is associated with dominance preference: results from a cross-sectional study of 1029 children. Braz J Phys Ther.2018.

6. Casselbrant ML, Mandel EM, Sparto PJ, Redfern MS, Furman JM. Contribution of vision to balance in children four to eight years of age. Ann OtolRhinolLaryngol. 2007; 116(9):653-657.

7. Libardoni, TC, da Silveira CB, Sinhorim LMB, de Oliveira AS, dos Santos MJ, Santos GM. Reference values and equations reference of balance for children of 8 to 12 years. Gait Posture. 2018; (60); 122-127.

8. Barela JÁ, Polastri PF, Godoi D. Postural control in children: body sway and its frequency. Rev Paul Educ Fís. 2000; 14(1):68-77.

9. Sparto PJ, Redfern MS, Jasko JG, Casselbrant ML, Mandel EM. Furman JM. The influence of dynamic visual cues for postural control in children aged 7-12 years. Exp Brain Res 2006; 168: 505-16.

10. Hsu YS, Kuan CC, Young YH. Assessing the development of balance function in children using stabilometry. Int. J. Pediatr. Otorhinolaryngol. 2009; 73: 737-740.

11. Fujiwara K, Kiyota T, Mammadova A, Yaguchi C. Age-related changes and sex differences in postural control adaptability in children during periodic floor oscillation with eyes closed. J. Physiol. Anthropol. 2011; 30: 187-194.

12. Kurz E, Faude O, Roth R, Zahner L, Donath L. Ankle muscle activity modulation during single-leg stance differs between children, young adults and seniors. Eur J ApplPhysiol. 2018 118(2), 239-247.

13. Steindl RMD, K Kunz MD, A Schrott-Fischer \& AW Scholtz. Effect of age and sex on maturation of sensory systems and balance control. DevMedChildNeuro 2006; 48: 477-482

14. Da Silva RA, Parreira RB, Medonça L, Ghizoni J, Vitor LG, Teixeira DC, et al. Developing validity and reliability of a new force plataform-based in balance measures in older and young adults. Society for Neuroscience. Proceeding in the 40 Neuroscience Meeting, San Diego, 2010 1206-7.

15. World Health Organization. 2007. Development of a WHO growth reference for school-aged children and adolescents. WHO Department of Nutrition, Geneva, CHE.
16. Mickle KJ, Munro BJ, Steele JR. Gender and age affect balance performance in primary school-aged children.J Sci Med Sport. 2011;14(3):243-8.

17. Andrew S, Ulmer F, Wong D. Gender differences in postural stability among children. J Hum Kinet 2012;33: 25-32.

18. Margherita T, Wiener-Vacher S, Bucci MP. Developmental study identifies the ages at which the processes involved in the perception of verticality and in postural stability occur. Acta Paediatr 2017;106.1: 55-60.

19. Matos MR, Matos CPG, Oliveira CS. Static balance of low vision children using stabilometric parameters. Fisioter. mov. (Impr.) 2010;23.3: 361-369.

20. Stins JF, Michielsen ME, Roerdink M, Beek PJ. Sway regularity reflects at10tional involvement in postural control: Effects of expertise, vision and cognition. Gait posture 2009; 30(1): 106-109.

21. Peterson ML, Christou E, Rosengren KS. Children achieve adultlike sensory integration during stance at 12 -years-old. Gait Posture. 2006; 23: 455-63.

22. Cuisinier R, Olivier I, Vaugoyeau M, Nougier V, Assaiante C. Reweighting of sensory inputs to control quiet standing in children from 7 to 11 and in adults. PLoS ONE. 2011; 6:19697.

23. Pavão SL, Santos AN, Oliveira AB, Rocha NACF. Postural control during sit-to-stand movement and its relationship with upright position in children with hemiplegic spastic cerebral palsy and in typically developing children. Braz J Phys Ther. 2015;19.1:18-25

24. Harbourne RT, Deffeyes JE, Kyvelidou A, Stergiou N. Complexity of postural control in infants: linear and nonlinear features revealed by principal component analysis. Nonlinear Dynamics Psychol Life Sci. 2009; 13:123-144.

25. Seemiller, E. S., Port, N. L., \& Candy, T. R. The gaze stability of 4-to 10-week-old human infants. J Vis. 2018; 18(8): 15-15.

26. Butz SM, Sweeney JK, Roberts PL, Rauh MJ. Relationships among age, gender, anthropometric characteristics, and dynamic balance in children 5 to 12 years old. Pediatr Phys Ther. 2015;27.2: 126-133

27. Ries LGK, Michaelsen SM, Soares PSA, Monteiro VC, Allegretti KMG. Cross-cultural adaptation and reliability analysis of the Brazilian version of Pediatric Balance Scale (PBS). Rev. bras. Fisioter. 2012; 16(3): 14.

\section{Corresponding author}

Leonardo George Victorio Vitor

Center for Health Sciences, Department of Physical Therapy, Avenida Robert Koch, n. 60, Vila Operária, 86039-440 Londrina, PR, Brazil. Email: leonardo@saudework.com.br

Manuscript received on September 7, 2018

Manuscript accepted on December 4, 2018

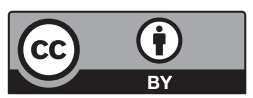

Motriz. The Journal of Physical Education. UNESP. Rio Claro, SP, Brazil - eISSN: 1980-6574 - under a license Creative Commons - Version 4.0 